\title{
TESTIMONIOS
}

\section{Discurso del Embajador Pablo Neruda Ante el Pen Club de Nueva York}

El siguiente es el texto completo del discurso que pronunciara Pablo Neruda en Nueva York ante el Pen Club de Estados Unidos, el 10 de abril de 1972:

Durante mi andariega vida he asistido a muchas reuniones extrañas. Hace unos días, sin embargo, estuve presente en la que me parece ha sido una de las más misteriosas conferencias en las cuales jamás he participado. Estuve sentado junto a un grupo de compatriotas. Frente a nosotros, en un vasto círculo ante nuestra vista, estaban los representantes de instituciones bancarias y de altos círculos financieros, delegados de diversos países a los cuales, según parece, mi país debe una gran cantidad de dinero. Nosotros, los chilenos, numéricamente inferiores a nuestros eminentes acreedores, casi todos de países importantes en mayor cantidad: probablemente cincuenta o sesenta. El asunto a tratar era la renegociación de nuestra Deuda Pública, de nuestra Deuda Externa, arrastrada a través de medio siglo por gobiernos anteriores.

En este medio siglo, los hombres han llegado a la luna, llenos de penicilina y televisión. En el campo bélico se ha inventado el napalm para someter a cenizas por la vía democrática de su fuego depurador, a numerosos habitantes de nuestro planeta. Durante estos mismos 50 años, el Centro Americano del Pen Club ha trabajado noblemente por la causa de la razón y el entendimiento. Pero como lo pude ver en esa inexorable reunión, Chile no era nada bajo la amenaza de la versión anticuada del garrote, llamado Stand-By. En vez de medio siglo de comprensión in telectual, las relaciones entre ricos y pobres, entre naciones que prestan algunas migajas de confort y otras que siguen hambrientas, continúan siendo una compleja mezcla de angustia y orgullo, injusticia y derecho a vivir. 
Existe un acuerdo entre los escritores de Estados Unidos y del Viejo Mundo, frente al cual tengo una posicion similar: es importante que todos reconozcamos lo que debemos hacer en favor de los otros. Debemos continuar renegociando, por así decirlo, la deuda interna que pesa sobre nosotros, los escritores del mundo. Cada uno de nosotros debe gran parte de su propia herencia intelectual, y mucho de lo que hemos adquirido, al tesoro cultural de toda la Humanidad. Los escritores de la mitad sur de este continente, como yo, han crecido y admirado, a pesar de la diferencia del idioma, el vasto desarrollo del mundo de las letras de esta mitad norteña. Hemos sido particularmente impactados por el admirable despertar de la novela, que, desde los días de Dreiser hasta el presente, ha mostrado una nueva fuerza, una fuerza convulsiva y constructiva cuya grandeza y fiereza no tiene parangón en la literatura de nuestra era, salvo entre vuestros propios escritores. Ninguno de vuestros grandes nombres ha sido desconocido por nosotros. Nombrarlos a todos sería una tarea interminable, como lo sería también tratar de medir la anchura de sus pensamientos, las violentas profundidades por ellos reveladas o la amarga desilusión mentida.

Vuestros libros, a menudo libros crueles, han exhibido el singular testimonio de nobles y grandes escritores, enfrentados con los conflictos, envueltos en el vertiginoso crecimiento de vuestra estructura capitalista. En esas obras ejemplares, nada de la verdad ha estado oculta: las almas de las multitudes y de los individuos, de los poderosos y de los débiles, en ciudades o suburbios, fueron expuestas desnudas las gotas de la verdadera sangre viva de vuestro cuerpo polntitico, de vuestras vi. das colectivas o solitarias. Aún en el campo de las narrativas detectivescas, que a menudo es más fiel testigo de la verdad de lo que uno pudiera pensar, estas cosas han salido a luz.

Por mi parte, yo, que tengo ahora cerca de 70 años, descubrí a Walt Whitman cuando tenía sólo 15, y lo consideré mi más grande acreedor. Estoy ante vosotros, sintiendo que le guardo para siempre la más grande y maravillosa deuda que me ha ayudado a existir.

Para renegociar esta deuda debo partir reconociendo su existencia, y reconociéndome como el humilde siervo de un poeta que abarcó la tierra con sus zancadas largas y lentas, deteniéndose en cualquier parte para amar, para estudiar, para aprender, para enseñar, para admirar. El hecho es que este gran hombre, este moralista lírico, eligió una difícil senda para él: fue tanto un cantor didáctico como torrencial, cualidades que parecen oponerse, y ser más apropiadas para un líder que para un escritor. Pero lo que realmente cuenta es que Walt Whit- 
man no tuvo miedo de enseñar lo que significa aprender a través de la vida y asumir la responsabilidad de traspasar la lección.

Hablando francamente, no tuvo miedo ni de ser un moralista ni de ser un inmoral, ni tampoco buscó separar los campos de la poesía pura e impura. Fue el primer poeta totalitario: su intención no fue otra que cantar, para imponer sobre otros su propia visión total y amplia de las relaciones de los hombres y de las naciones. En este sentido, su nacionalismo patente forma parte de una visión universal total y orgánica: se juzgó a sí mismo un deudor tanto de la felicidad como del dolor, y también de las culturas avanzadas como de las sociedades más primitivas.

Existen muchas clases de grandezas, pero déjenme decirles (aun cuando soy un poeta de habla hispana) que Walt Whitman me ha enseñado más que el Cervantes español. En la obra de Walt Whitman nunca el ignorante es humillado, ni la condición humana jamás ofen. dida.

Continuamos viviendo una era whitmanesca, viendo cómo nuevos hombres y nuevas sociedades surgen y crecen, a pesar de sus dolores de parto. La queja del bardo era sobre la poderosa influencia de Europa de la cual la literatura de su época continuó obteniendo su sustento. En verdad él, Walt Whitman, fue el protagonista de una verdadera personalidad geográfica: el primer hombre de la historia en hablar con auténtica voz americana continerital, en sustentar un auténtico nombre americano. Las colonias de los países más brillantes han dejado un legado de siglos de silencio: el colonialismo parece matar la fertilidad y embrutecer el poder de creación. Uno tiene sólo que mirar hacia el Imperio español, donde yo les puedo asegurar que tres siglos de dominio produjeron no más de tres: escritores de valía en toda América.

La proliferación de nuestras repúblicas dio nacimiento a algo más que banderas y nacionalidades, pequeños ejércitos heroicos y melancólicas canciones de amor. Comenzaron también a circular libros, aun cuando muy a menudo formaron un bosque impenetrable con muchas flores, pero pocos frutos. Sin embargo, con el tiempo y especialmente en nuestros días, la lengua castellana al fin ha comenzado a brillar en las obras de escritores que, desde el Río Grande a la Patagonia, han llenado toda la obscuridad del continente (luchando hacia una nueva independencia) con mágicas historias, y con poemas ora tienos, ora desesperados.

En estos días, nosotros vemos cómo otras nuevas naciones, otras nuevas literaturas y otras nuevas banderas, coinciden con nuestras esperanzas de la total extinción del colonialismo en Africa y Asia. Casi de la noche a la mañana, las capitales del mundo han visto banderas 
de pueblos que nunca antes conocimos buscando su auto-expresión con la voz áspera y cargada de dolor del nacimiento. Escritores negros, tanto de Africa como de América, comienzan a darnos el verdadero pulso de las razas desgraciadas, hasta ahora silenciosas. Las luchas políticas han sido siempre inseparables de la poesía. La liberación del hombre puede exigir a veces derramamientos de sangre, pero siempre necesita canto y el canto de la humanidad se enriquece día a día, en esta era de sufrimientos y liberación.

Les pido perdón, humildemente, de antemano, por referirme al tema de los problemas de mi Patria. Como todo el mundo sabe, Chile está en camino de llevar a cabo una transformación revolucionaria de su estructura social con verdadera dignidad, y dentro del marco de nuestra constitución legal. Esto es algo que sorprende $\mathfrak{u}$ ofende a mucha gente. ¿Por qué, preguntan, estos chilenos cargantes no encarcelan a alguien, no cierran diarios, o fusilan a los que están contra ellos?

Como nación, nosotros elegimos el camino y por esa misma razón estamos resueltos a seguir hasta el final. Pero secretos enemigos usan cualquier clase de arma para cambiar nuestro destino. Como parece que los cañones están fuera de moda en esta clase de guerra, usan un arsenal completo de armas, tanto antiguas como nuevas. Dólares y flechas, teléfonos y servicios telegráficos; todo parece servir. Parece como si todo fuera permitido, cuando se trata de defender viejos e incomprensibles privilegios. Ese es el porqué, cuando estuve sentado en esa reunión en que Chile renegociaba su Deuda Externa en París, no pude dejar de pensar vivamente en $E l$ Viejo Marinero.

Samuel Taylor Coleridge sacó de un episodio ocurrido en el extremo sur de mi país (registrado en los viejos de Shelvocke) la inspiración para su poema desolado.

En los fríos mares de Chile tenemos toda clase de albatros: errantes, gigantes, grises y obscuros y de supremo esplendor en sus vuelos.

Esa es, quizás, la razón del porqué mi país tiene la forma de un gran albatros, con sus alas extendidas.

$Y$ en esa inolvidable reunión, en la cual tratábamos de renegociar nuestra Deuda Externa en forma justa, muchos de los que se portaban como implacables, parecian tener como objetivo derribar a Chile a fin de que el albatros no pudiera jamás volver a volar.

Contar esto puede ser indiscreción de un poeta que ha sido Embajador durante un año, pero me pareció como si el representante de las finanzas norteamericanas hubiera sido quien escondía una flecha bajo su carpeta de documentos, listo para disparar contra el corazón del alba- 
tros. Sin embargo, este financista tenía un nombre agradable (uno que sonaria muy bien al final de un banquete) : se llamaba Mr. Hennessy.

$Y$ si se hubiera dado la molestia de releer a los poetas de antiguos tiempos, habría sabido, por El Viejo Marinero, que el que perpetró tal crimen fue condenado a llevar el pesado cuerpo del albatros asesinado, colgando de sus hombros, por toda una eternidad.

Queridos amigos:

He leído la breve historia de los largos 50 años de vida del Pen Club Americano, tanto con interés como con verdadera emoción. Ha sido medio siglo de grandes esperanzas y espléndidos logros: una jornada noble y honrosa que debemos celebrar con meditación y con alegría. Los escritores son todos muy fácilmente individualistas, muy raramente colectivistas: llevamos dentro de nosotros un germen de subversión que forma parte de nuestro íntimo ser y la expresión de nuestra rebelión a menudo parece volverse contra nosotros mismos. Buscamos los enemigos más cercanos y erróneamente escogemos entre aquéllos que se nos parecen. Para nosotros, caminar juntos es labor de gigantes. Y caminar juntos por encima de fronteras políticas, lingüísticas y raciales los enemigos más cercanos y erróneamente escogemos entre aquéllos que han hecho posible a los escritores de todos los países experimentar la sensación de sentirse únicos, sin renunciar a sus propias tendencias o creencias.

Estoy seguro que Uds. me han recibido aquí a mí y a mis deudas no como un implacable tribunal, sino como una generosa y fraternal asociación. He dicho ya que es digno de nosotros reconocer lo que hemos aprendido: de otro, o de todos. Esta es la única forma en que puede establecerse una ininterrumpida comunidad universal de pensamiento, segura y consciente.

Por eso debemos colaborar con el pasado, seguros de su bella madurez e igualmente seguros de la senda que pisamos con honor y a la espera de otras obras que serán escritas por otros autores y para otros hom. bres que todavía no han venido al mundo. 
